\title{
Assessments of Neoadjuvant Hormone Therapy Followed by Robotic-Assisted Radical Prostatectomy for Intermediate- and High-Risk Prostate Cancer
}

\author{
JU-CHUAN HU, SHENG-CHUN HUNG and YEN-CHUAN OU \\ Division of Urology, Department of Surgery, Taichung Veterans General Hospital, Taichung, Taiwan, R.O.C.
}

\begin{abstract}
Background/Aim: It is still unclear whether neoadjuvant hormone therapy (NHT) followed by radical prostatectomy is the best treatment option for advanced prostate cancer. This study aimed to evaluate the benefits of NHT followed by robotic-assisted laparoscopic radical prostatectomy $(\mathrm{RaLP})$ in locally advanced prostate cancer. Patients and Methods: This study included 48 patients that had received NHT prior to RaLP by a single surgeon. The control group was selected using computerized 1:1 ratio matching. General characteristics, peri-operative parameters, and oncologic outcomes were analyzed retrospectively. Results: Significantly shorter operative time, lesser blood loss and lower positive surgical margins were reported in the $N H T$ group. The median period to biochemical recurrence $(B C R)$ was shorter (3 months vs. 5 months, $p=0.0145)$ and the overall BCR rate was lower $(54.17 \%$ vs. $87.5 \%$, $p=0.0243)$. Conclusion: NHT followed by RaLP may provide clinicopathological benefits, especially in patients with preoperative PSA values between 10-20 and above 50. Further prospective studies are needed to assess the impacts of NHT.
\end{abstract}

Current guidelines have established that patients with intermediate- or high-risk prostate cancer $(\mathrm{CaP})$ could be offered neoadjuvant, concurrent, and adjuvant hormone therapy if receiving definitive radiation therapy. Conceptually, neoadjuvant treatment could offer theoretical benefits not only for reducing the tumor size, but also treating undetected micro-metastases (1). These benefits

This article is freely accessible online.

Correspondence to: Prof. Yen-Chuan Ou, Division of Urology, Department of Surgery, Taichung Veterans General Hospital, No. 1650, Sec. 4, Taiwan Boulevard, 40705, Taichung, Taiwan, R.O.C. Tel: +886 4235925255121, e-mail: ycou228@gmail.com

Key Words: Prostate cancer, neoadjuvant, hormone therapy, robotic, radical prostatectomy. could contribute to a higher possibility of free surgical margin and may result in improved progression-free survival. Therefore, considerable research efforts have been expended to determine whether neoadjuvant therapy improves clinical outcomes in $\mathrm{CaP}$.

Certain studies have shown favorable effects with respect to lower positive surgical margin and pathological downstaging in patients with locally advanced $\mathrm{CaP}$ who received neoadjuvant hormone therapy (NHT) followed by either conventional or laparoscopic radical prostatectomy (2-6). With the exception of few non-randomized trials, most of these studies failed to provide evidence that NHT contributes to lower incidences of biochemical recurrence and disease progression (7-14).

The regimens of neoadjuvant therapy varied among these studies and included single use of LHRH agonists, combined therapy with LHRH agonists plus anti-androgen agents (15), chemotherapy alone or chemohormone therapy (16-20). However, there are currently no sufficient evidence to show that NHT could benefit patients receiving robotic-assisted laparoscopic radical prostatectomy (RaLP).

The purpose of this study was to assess the clinicopathological results of patients that received NHT prior to RaLP, especially for D'Amico intermediate- and high-risk patients. We also attempted to identify which populations of patients with CaP might benefit from NHT.

\section{Patients and Methods}

Between January 2008 and June 2014, men with D'Amico intermediate- or high-risk CaP who received RaLP in Taichung Veterans Generals Hospital were retrospectively reviewed. The patients that were enrolled in the study had received hormone therapy before surgical intervention. The decision of prescribing NHT or not was made by the same surgeon according to the oncologic risks.

Exclusion criteria included patients who had received NHT initially prescribed by other surgeons, patients who had taken $5-\alpha-$ reductase inhibitors or neoadjuvant chemotherapy prior to RaLP, patients with poor cardiopulmonary functions and poor performance status (i.e., Eastern Cooperative Oncology Group [ECOG] worse than 
Grade I), and patients with strong evidences of distant metastasis. Regimens of neoadjuvant hormone therapy. NHT regimens include combinations of Luteinising hormone-releasing hormone (LHRH) agonists with anti-androgens and individual use of either an LHRH agonist or anti-androgens. The duration of NHT was determined by the responses of PSA reductions and subjective tumor size reductions at digital rectal exams by the same surgeon. The eligible duration of NHT therapy varied from 2 months to 12 months.

The regimens of androgen deprivation therapy included LHRH agonists (either LEUPLIN ${ }^{\circledR}$ [Leuprorelin acetate], 3.75/month or ZOLADEX $^{\circledR} \quad$ [goserelin acetate implant], $3.6 \mathrm{mg} / \mathrm{month}$, subcutaneous injection) with or without anti-androgen agents (CASODEX ${ }^{\circledR}$ [bicalutamide] $50 \mathrm{mg} /$ day, or Cyprostat ${ }^{\circledR}$ [Cyproterone acetate] $50 \mathrm{mg} /$ day, oral form).

Propensity score methodology. We used a propensity score analysis to reduce the effects of selection biases and potential confounding factors in this retrospective study. Propensity scores were calculated for each patient using a multivariate logistic regression according to the following covariates: (i) prostate-specific antigen (PSA) level at diagnosis, (ii) Gleason score by prostate biopsy, (iii) clinical stage (iv), age (v), BMI. The control groups from our Taichung Veterans Generals Hospital Prostate Cancer Database were then matched with the NHT group based on their calculated propensity scores.

The clinical stages were diagnosed by certified radiologists in combined conferences after carrying out digital rectal palpations, bone scans, and magnetic resonance images. The patients with T4 tumor or distant metastasis, and those who received salvage prostatectomy, neoadjuvant chemotherapy or other neoadjuvant therapy were all excluded from the study.

All patients received RaLP by the same surgeon. Neurovascular bundles (NVB) were preserved only if there were organ-confined lesions in both MRI and digital rectal examination to guarantee sufficient distances for safe margin. General characteristics of patients, peri-operative parameters, as well as oncologic outcomes were prospectively recorded. All prostatectomy specimens were sectioned by the whole mount technique to evaluate the surgical margin.

PSA biochemical recurrence (BCR) was defined as two consecutive measurements of PSA $>0.2 \mathrm{ng} / \mathrm{ml}$ while the first PSA $>0.2 \mathrm{ng} / \mathrm{ml}$ was documented as the date of BCR. If PSA level did not decrease to $<0.2 \mathrm{ng} / \mathrm{ml}$ at the first month post-operative, we rechecked the PSA level one month later (i.e., 2 months after operation). If PSA level was still over $0.2 \mathrm{ng} / \mathrm{ml}$, the date of surgery was viewed as the date of BCR. If BCR was identified within postoperative 3 months, it was defined as an early BCR and suggested treatment failure. Continence was defined as no use of pad.

The numerical variables were tested with Man-Whitney $U$-test and the qualitative data was tested with Fisher's extract test. The biochemical recurrence-free (BCR-free) survival was estimated with the Kaplan-Meier method and the relationship between survival and subgroup classification was analyzed using the log-rank test. Univariate and multivariate analysis were performed using a logistic regression model. A statistical significance was defined as a $p$-value less than 0.05 .

\section{Results}

Patients' characteristics. A total of 48 patients were included. Twenty-four patients who received NHT prior to surgery were enrolled first and another 24 patients who underwent RaLP only were selected from our database via the propensity score methodology. The clinical features are displayed in Table I.

The median age was 66.5 and 65.5 for the control group and NHT group, respectively ( $p=0.348)$. The median PSA level at diagnosis was $44.3 \mathrm{ng} / \mathrm{ml}$ in the control group and $36.35 \mathrm{ng} / \mathrm{ml}$ in the NHT group $(p=0.902)$. There were no significant differences between the groups in body size, Gleason score at biopsy, and tumor percentages of all biopsy specimens. With respect to clinical stages, the control group included more cT2c stage (50\% in the control group vs. $20.83 \%$ in NHT group), while the NHT group had a greater percentage of cT3b stage (12.5\% in the control group vs. 33.33\% in the NHT group).

This study has the Institute With Human Ethical Issue approval (Taichung Veterans General Hospital, Taichung, Taiwan, ROC). The institute review board number was CE15215B.

Peri-operative outcome. The total operative periods and times for anastomosis were both significantly shorter in the NHT group. The other peri-operative results are shown in Table II.

Pathological outcome. The median tumor percentage in whole prostate specimens was significantly lower in the NHT group (control vs. NHT: $70 \%$ vs. $30 \%, p=0.0398$ ). There is a significant lower positive surgical margin in the NHT group (control vs. NHT: $91.67 \%$ vs. 37.5\%, $p=0.0002$ ). Significantly smaller prostate volumes in the NHT group were also reported, but there was no significant difference between these two groups in extracapsular invasion, bladder neck (BN), seminal vesicle (SV) and prostate urethra invasion. The Gleason score in the majority of patients in both groups was 9 . The pathologic stage was upgraded in both groups with a higher percentage of T3/T4 in the control group $(95.83 \%$ in the control group $v s$. $75 \%$ in the NHT group, $p=0.097$ ). There are no differences in lymphoadenopathy between the two groups.

Oncologic outcome. Of the 48 eligible patients, no patients deceased during the follow-up period. The median follow-up period was 44.5 months in the control group versus 18.5 months in the NHT group $(p<0.0001)$. This limitation might have contributed to a confounding effect on the oncologic outcome, which would be discussed later.

There were lower incidences of biochemical recurrences in the NHT group (median BCR in control group $v s$. NHT group: $87.5 \%$ vs. $54.17 \%(p=0.0243)$. The hazard ratio of overall BCR-free survival in the NHT group was 0.404 (range $=0.203-0.803$ ),$p=0.0047$ (Figure 1a).

We also found a significantly decreased rate of BCR in patients who received 4-12 months of NHT compared to patients receiving 2-3 months of NHT (Figure 1b). The hazard ratio of BCR-free survival was $0.519(0.228-1.182)$ in patients who received NHT for 2-3 months, and 0.298 $(0.134-0.665)$ in the NHT 4-12 months group $(p=0.0133)$. 
Table I. Patients characteristics.

\begin{tabular}{|c|c|c|c|}
\hline & $\begin{array}{c}\text { Control } \\
(\mathrm{n}=24)\end{array}$ & $\begin{array}{c}\text { NHT } \\
(n=24)\end{array}$ & $p$-Value \\
\hline Age (year-old) & $66.50(63.00-70.50)$ & $65.50(58.5-73.50)$ & 0.348 \\
\hline Body height $(\mathrm{cm})$ & $165.00(160.25-167.25)$ & $165.25(161.50-169.00)$ & 0.509 \\
\hline Body weight $(\mathrm{kg})$ & $66(60.5-72.5)$ & $67.5(60.5-75.6)$ & 0.7966 \\
\hline BMI & $24.45(22.70-26.54)$ & $24.05(22.53-26.69)$ & 0.665 \\
\hline ASA & & & 0.49 \\
\hline I & $2(8.33 \%)$ & $2(8.33 \%)$ & \\
\hline II & $19(79.17 \%)$ & $21(87.5 \%)$ & \\
\hline III & $3(12.5 \%)$ & $1(4.17 \%)$ & \\
\hline Initial PSA (ng/ml) & $44.30(25.63-72.30)$ & $36.35(24.82-77.82)$ & 0.9015 \\
\hline \multicolumn{4}{|l|}{ NHT period (months) } \\
\hline $2-3$ mon & - & $12(50 \%)$ & \\
\hline 4-12 mon & - & $12(50 \%)$ & \\
\hline Initial GS at biopsy & & & 0.4687 \\
\hline $\mathrm{GS}=6$ & $1(4.17 \%)$ & $2(8.33 \%)$ & \\
\hline $\mathrm{GS}=7$ & $7(29.17 \%)$ & $5(20.83 \%)$ & \\
\hline $\mathrm{GS}=8$ & $4(16.67 \%)$ & $2(8.33 \%)$ & \\
\hline $\mathrm{GS}=9$ & $10(41.67 \%)$ & $14(58.33 \%)$ & \\
\hline $\mathrm{GS}=10$ & $2(8.33 \%)$ & $1(4.17 \%)$ & \\
\hline Initial clinical $\mathrm{T}$ stage & & & 0.1044 \\
\hline cT2b & $1(4.17 \%)$ & $2(8.33 \%)$ & \\
\hline $\mathrm{cT} 2 \mathrm{c}$ & $12(50 \%)$ & $5(20.83 \%)$ & \\
\hline cT3a & $8(33.33 \%)$ & $9(37.5 \%)$ & \\
\hline $\mathrm{cT} 3 \mathrm{~b}$ & $3(12.5 \%)$ & $8(33.3 \%)$ & \\
\hline Initial tumor (\%) at biopsy & $52.5(31.25-72.50)$ & $41.5(22.50-70)$ & 0.4578 \\
\hline Post-NHT PSA reduction (\%) & - & $98.68(90.80-99.74)$ & - \\
\hline
\end{tabular}

BMI: body mass index; ASA: American Society of Anesthesiologists Physical Status classification; PSA: prostate specific antigen; NHT: neoadjvant hormone therapy; GS: Gleason Score. Note: Mann-Whitney $U$-test for continuous variables[Median (IQR)] and Fisher's extract test for categorized variables[number (\%)], statistical significance $p<0.05^{*}$.

\section{Discussion}

Takeda and his colleagues had shown that neoadjuvant hormone therapy could significantly shorten the pneumoperitoneum time (NHT vs. radical prostatectomy alone: $164.5 \pm 39.0 \mathrm{~min} v s .184 .0 \pm 36.7 \mathrm{~min}, p=0.048)$ and reduce the prostate volume by $33.9 \%$ in the NHT group (21). Their multivariate analysis demonstrated that NHT was an independent factor for longer pneumoperitoneal time in patients with larger prostate volume.

We found that the median periods of anastomosis were $20 \min v s .25 \min (p=0.0015)$ and the overall operation time was $115 \mathrm{~min} v s .145 \mathrm{~min}(p=0.0018)$. Both were significantly shorter in the NHT group. There was not only less blood loss ( $50 \mathrm{ml} v s .110 \mathrm{ml}, p=0.0263)$ but also smaller median specimen volume in the NHT group ( $35 \mathrm{ml} v s .40$ $\mathrm{ml}, p=0.0302$ ).

The single surgeon in this study performed his first RaLP in 2008 and at the time of writing had performed over 1500 cases of RaLP (22). The surgeon's accumulation of surgical experience and skills over time which might have contributed to shorter operative times and a better pentafecta outcomes (complication-free, continence, potency, negative surgical margins, BCR-free) (23). Moreover, prostate shrinkage after NHT might also have affected operative time.

Although the maturing experiences of the single surgeon and the downsizing volume of prostate specimen may play an important role in shortening the operative time and reducing blood loss, there is typically considerable severe tissue adhesion after NHT, which tends to increase the difficulty of surgery and might lead to a longer operative time and more blood loss. However, the importance of the above mentioned confounding factors were difficult to evaluate.

Although there are no clear guidelines or level I evidence to show that NHT is unequivocally beneficial in patients with $\mathrm{CaP}$, many studies have suggested the possible advantages of NHT followed by radical prostatectomy with respect to free surgical margin.

One prospective study enrolled 69 patients that had received androgen deprivation therapy for 3 months followed by radical prostatectomy and 72 patients received radical prostatectomy (4). They disclosed lower rate of marginnegative tumor in the control group (64\% in control group and 
Table II. Clinicopathologic outcomes.

\begin{tabular}{|c|c|c|c|}
\hline & $\begin{array}{c}\text { Control } \\
(\mathrm{n}=24)\end{array}$ & $\begin{array}{l}\text { NHT } \\
(n=24)\end{array}$ & p-Value \\
\hline Operative time (minutes) & $145(110-195)$ & $115(100-125)$ & $0.0018^{*}$ \\
\hline Anastomosis time (minutes) & $25(20-35)$ & $20(15-20)$ & $0.0015^{*}$ \\
\hline Blood loss (ml) & $110(50-200)$ & $50(42.5-100)$ & $0.0263 *$ \\
\hline Catheterization (days) & $10(8-12)$ & $7(7-8)$ & $0.002 *$ \\
\hline Hospitalization (days) & $3(3-3.5)$ & $3(3-4)$ & 0.6964 \\
\hline Specimen volume (gm) & $40(35-57.5)$ & $35(31.5-41.5)$ & $0.0302 *$ \\
\hline Tumor percentage $(\%)$ & $70(30-90)$ & $30(7.5-80)$ & $0.0398 *$ \\
\hline Tumor volume (gm) & $30(9.98-43.7)$ & $9.25(2.5-29.2)$ & $0.0109 *$ \\
\hline GS at prostatectomy & & & 0.9817 \\
\hline $\mathrm{GS}=6$ & $0(0 \%)$ & $2(8.33 \%)$ & \\
\hline $\mathrm{GS}=7$ & $8(33.33 \%)$ & $4(16.67 \%)$ & \\
\hline $\mathrm{GS}=8$ & $1(4.17 \%)$ & $3(12.5 \%)$ & \\
\hline $\mathrm{GS}=9$ & $14(58.33 \%)$ & $14(58.33 \%)$ & \\
\hline $\mathrm{GS}=10$ & $1(4.17 \%)$ & $1(4.17 \%)$ & \\
\hline Pathological $\mathrm{T}$ stage & & & $0.0231 *$ \\
\hline pT2a & $0(0 \%)$ & $1(4.17 \%)$ & \\
\hline pT2b & $0(0 \%)$ & $1(4.17 \%)$ & \\
\hline pT2c & $1(4.17 \%)$ & $4(16.67 \%)$ & \\
\hline pT3a & $3(12.5 \%)$ & $4(16.67 \%)$ & \\
\hline pT3b & $18(75 \%)$ & $14(58.33 \%)$ & \\
\hline pT4a & $2(8.33 \%)$ & $0(0 \%)$ & \\
\hline Positive surgical margin & $22(91.67 \%)$ & $9(37.5 \%)$ & $0.00017 *$ \\
\hline Extracapsular invasion & $23(95.83 \%)$ & $20(83.33 \%)$ & 0.3475 \\
\hline Bladder neck invasion & $9(37.5 \%)$ & $10(41.67 \%)$ & 1 \\
\hline Prostate urethra invasion & $9(37.5 \%)$ & $5(20.83 \%)$ & 0.3411 \\
\hline Seminal vesical invasion & $19(79.17 \%)$ & $14(58.33 \%)$ & 0.2124 \\
\hline Perineural invasion & $24(100 \%)$ & $22(91.67 \%)$ & 0.4894 \\
\hline Angiolymphatic invasion & $11(45.83 \%)$ & $4(16.67 \%)$ & 0.0599 \\
\hline Multicenricity of tumor & $17(70.83 \%)$ & $18(75 \%)$ & 1 \\
\hline High grade PIN & $14(58.33 \%)$ & $6(25 \%)$ & $0.0392 *$ \\
\hline LAP & $4(16.67 \%)$ & $4(16.67 \%)$ & 1 \\
\hline $\mathrm{BCR}$ & $21(87.5 \%)$ & $13(54.17 \%)$ & $0.0243 *$ \\
\hline Early BCR (within 3 months) & $12(57.14 \%)$ & $1(7.69 \%)$ & $0.0048 *$ \\
\hline Average BCR period (months) & $3(2-4.75)$ & $5(4-8.25)$ & $0.0145^{*}$ \\
\hline Follow-up period (months) & $44.5(34-73)$ & $18.5(11.5-26.5)$ & $<0.0001 *$ \\
\hline \multicolumn{4}{|l|}{ BCR in different PSA level } \\
\hline PSA $10-20$ & $2 / 3(66.67 \%)$ & $0 / 5(0 \%)$ & $0.0486^{*}$ \\
\hline PSA 21-50 & $9 / 11(81.82 \%)$ & $8 / 10(80 \%)$ & 0.9175 \\
\hline PSA $>50$ & $10 / 10(100 \%)$ & $5 / 9(55.56 \%)$ & $0.0209 *$ \\
\hline \multicolumn{4}{|l|}{ Early BCR in different PSA level } \\
\hline PSA $10-20$ & $1 / 2(50 \%)$ & $0 / 5(0 \%)$ & 0.1138 \\
\hline PSA $21-50$ & $4 / 9(44.44 \%)$ & $0 / 8(0 \%)$ & $0.0365 *$ \\
\hline $\mathrm{PSA}>50$ & $7 / 10(70 \%)$ & $1 / 5(20 \%)$ & 0.0771 \\
\hline
\end{tabular}

GS: Gleason Score; PIN: prostatic intraepithelial neoplasia; LAP: lymphoadenopathy; BCR: biochemical recurrence. Note: Mann-Whitney $U$-test for continuous variables[Median (IQR)] and Fisher's extract test for categorized variables[number (\%)], statistical significance $p<0.05^{*}$.

$87 \%$ in neoadjuvant group, $p<0.01)$ and higher organ-confined (pT2) tumor in neoadjuvant group $(74 \%$ vs. $49 \%, p<0.01)$. However, like most of the other researches, this study did not show a lower biochemical recurrence in the neoadjuvant group within a median follow up period of 35 months.

In this study, we attempted to prove the potential therapeutic advantages of NHT and identify which populations of patients with $\mathrm{CaP}$ might benefit from NHT using this single surgeon database. We found lower incidences of biochemical recurrences in the NHT group $(54.17 \%$ vs. $87.5 \%, p=0.0243)$. When we stratified the data based on the timing of BCR, we found that early BCR (failed to achieve PSA $<0.2 \mathrm{ng} / \mathrm{ml}$ in post-OP three months) was higher in the control group (control vs. NHT: $57.14 \%$ vs. $7.69 \%, p=0.0048$ ). Strictly 

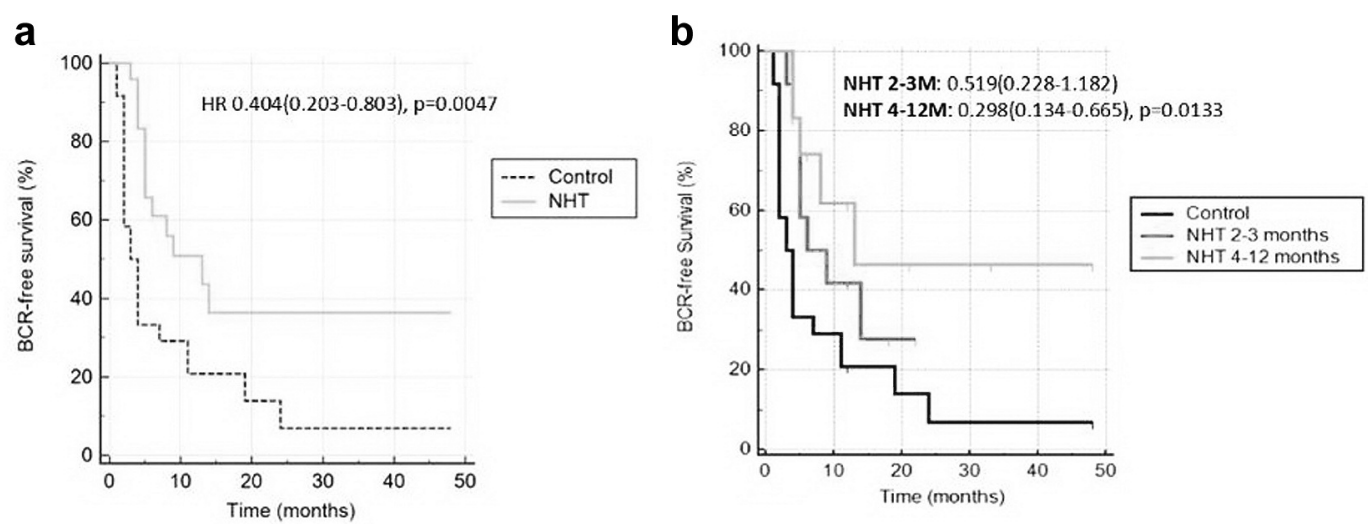

Figure 1. Kaplan-Meier estimates of biochemical recurrence-free survival. 1a) Control group vs. NHT group. 1b) Control group vs. two different NHT groups.

speaking, the overall incidences of BCR were significantly lower in the NHT group and most of them occurred at least 3 months after RaLP (12/13, 92.31\%).

When we grouped the patients by the level of pre-treatment PSA (see Table II), we found that patients with pre-treatment PSA $10-20 \mathrm{ng} / \mathrm{ml}$ and PSA $>50 \mathrm{ng} / \mathrm{ml}$ had lower overall BCR rate if they received NHT prior to RaLP (PSA 10-20 ng/ml group: control vs. NHT $=66.67 \% v s .0 \%, p=0.0486$. PSA $>50$ $\mathrm{ng} / \mathrm{ml}$ group: control vs. NHT: $100 \%$ vs. $55.56 \%, p=0.0209)$. However, we did not found a similar significant benefit in patients with pre-treatment PSA 20-50 ng/ml (control vs. NHT $=81.82 \%$ vs. $80 \%, p=0.9175)$.

With regard to the proportion of early BCR in all patients having BCR grouped according to PSA levels, four patients had early BCR $(4 / 9,44.44 \%)$ in the PSA $20-50 \mathrm{ng} / \mathrm{ml}$ group and seven patients had early BCR $(7 / 10,70 \%)$ in the PSA $>50 \mathrm{ng} / \mathrm{ml}$ group if they did not receive NHT. In patients receiving NHT, no patient had early BCR $(0 / 8,0 \%)$ in both PSA $10-20$ and $20-50 \mathrm{ng} / \mathrm{ml}$ groups while only one patient in the PSA $>50 \mathrm{ng} / \mathrm{ml}$ group $(1 / 5,20 \%)$ had early BCR. These results suggest that decreased risk of $\mathrm{BCR}$ and potential delayed BCR can be achieved in patients receiving NHT with pre-treatment PSA 10-20 ng/ml and PSA >50 ng/ml. In patients with pre-treatment PSA $20-50 \mathrm{ng} / \mathrm{ml}$, NHT did not reduce the incidence of BCR but might delay the timing of BCR. These findings suggest that NHT might help slowing the disease progression in locally advanced $\mathrm{CaP}$.

The potential for delayed biochemical recurrence in the NHT group was considered to be related to the residual inhibition from prior hormone therapy. MG Oefelein et al. (24) disclosed that a single injection of 3-month formulation of LHRH agonist would provide castrate level of testosterone for six months. Hall MC et al. (25) reported that residual suppression on luteinizing hormone and castrate effects of testosterone could persist up to one years after discontinuation. In a study by Koie T et al. (26), the testosterone levels in patients who received NHT returned to the pre-treatment level six months after discontinuing medications.

The residual suppression of testosterone by NHT might help to slow the biochemical recurrence. However, there are higher possibilities of surgical treatment failure (either PSA wasn't less than $0.2 \mathrm{ng} / \mathrm{ml}$ within 2 months after RaLP or early BCR within 3 months after RaLP) in patients with preoperative PSA $20-50 \mathrm{ng} / \mathrm{ml}$ and PSA $>50 \mathrm{ng} / \mathrm{ml}$. These patients can benefit from NHT as it appears to lower PSA level before operation and also to delay BCR. Unfortunately, testosterone level was not routinely followed up after RaLP and thus it was not possible to analyze the durations of residual effects from androgen deprivation therapy.

Currently, there is no consensus about the proper durations of NHT due to lack of evidences. One randomized control trial directly comparing the durations of NHT prescription suggested that the optimal duration was longer thant 3 months (27). Cochrane review concluded that the use of longer duration of NHT, that is either 6 or 8 months prior to prostatectomy, was associated with a significant reduction in positive surgical margins $(\mathrm{OR}=0.56,95 \% \mathrm{CI}=0.39-0.80$, $p=0.002)(28)$.

We found that patients who received 4-12 months of NHT had significantly decreased rate of BCR compared to patients receiving 2-3 months of NHT (Figure 1b). These results were compatible to prior studies. Meyer F et al. disclosed lower risk of $\mathrm{BCR}$ in patients receiving NHT for more than 3 months $(\mathrm{HR}=0.52,95 \% \mathrm{CI}=0.29-0.93)$ (29).

The testosterone levels in all patients in the NHT group achieved castration level after one month of NHT, which might suggest that patients should receive NHT before RaLP for longer than 3 months to achieve maximum protection effects. 
Table III. Univariate and multivariate Cox proportional hazard regression analysis for prediction of biochemical recurrence.

\begin{tabular}{|c|c|c|c|c|c|c|}
\hline & \multicolumn{3}{|c|}{ Univariate } & \multicolumn{3}{|c|}{ Multivariate } \\
\hline & HR & $95 \% \mathrm{CI}$ & $p$-Value & $\mathrm{HR}$ & $95 \% \mathrm{CI}$ & $p$-Value \\
\hline Age & 0.9958 & 0.9566 to 1.0366 & 0.8366 & & & \\
\hline BMI & 1.0493 & 0.9317 to 1.1817 & 0.4277 & & & \\
\hline Initial PSA & 1.008 & 0.9994 to 1.0167 & 0.0679 & 1.0011 & 0.9908 to 1.0116 & 0.8287 \\
\hline NHT or Not & 0.3962 & 0.1970 to 0.7967 & $0.0094 *$ & 0.4627 & 0.1554 to 1.3777 & 0.1662 \\
\hline Pre-OP GS & 1.2385 & 0.8900 to 1.7236 & 0.2046 & & & \\
\hline Tumor $\%$ & 1.0229 & 1.0116 to 1.0344 & $0.0001 *$ & 1.0183 & 0.9990 to 1.0379 & 0.0636 \\
\hline Capsule & 3.1982 & 0.7643 to 13.3827 & 0.1114 & 0.8304 & 0.1380 to 4.9971 & 0.8391 \\
\hline SV & 2.8151 & 1.2031 to 6.5869 & $0.017 *$ & 0.81 & 0.1848 to 3.5506 & 0.7799 \\
\hline $\mathrm{BN}$ & 1.825 & 0.9155 to 3.6381 & 0.0874 & 1.2043 & 0.4260 to 3.4044 & 0.7259 \\
\hline PIN & 1.0452 & 0.5267 to 2.0744 & 0.8993 & & & \\
\hline PNI & 2.1867 & 0.2977 to 16.0609 & 0.4419 & & & \\
\hline ALI & 2.9122 & 1.4372 to 5.9010 & $0.003^{*}$ & 0.7998 & 0.2747 to 2.3292 & 0.6822 \\
\hline PSM & 4.4981 & 1.8134 to 11.1574 & $0.0012 *$ & 1.2927 & 0.3011 to 5.5502 & 0.7298 \\
\hline LAP & 1.9442 & 0.8289 to 4.5601 & 0.1264 & 1.944 & 0.4987 to 7.5783 & 0.3382 \\
\hline NVB preserving & 0.3196 & 0.0435 to 2.3482 & 0.2622 & & & \\
\hline Operative time & 1.0132 & 1.0046 to 1.0218 & $0.0025 *$ & 1.0087 & 0.9968 to 1.0207 & 0.153 \\
\hline Post-operative PSA & 1.0481 & 1.0118 to 1.0857 & 0.009 & 1.0116 & 0.9662 to 1.0590 & 0.6227 \\
\hline Post-operative GS & 1.0105 & 0.7386 to 1.3825 & 0.9479 & & & \\
\hline
\end{tabular}

†BMI: body mass index; PSA: prostate specific antigen; NHT: neoadjvant hormone therapy; GS: Gleason Score; SV: seminal vesicals; BN: bladder neck; PIN: prostatic intraepithelial neoplasia; PNI: perineural invasion; ALI: angiolymphatic invasion; PSA: positive surgical margin; LAP: lymphoadenopathy; NVB: neurovascular bundles. Statistical significance $p<0.05^{*}$.

In univariate analysis for evaluating the predictive factors of biochemical recurrence (Table III), we found that NHT, tumor percentages in specimen, seminal vesicles involvements, angiolymphatic invasion, positive surgical margin and operative times influence BCR. However, we couldn't identify any statistically significant predictors in multivariate logistic regressions. Further larger studies are needed for identifying the accurate predictors to help clinicians making decisions abour NHT or not in locally advanced $\mathrm{CaP}$.

There were several limitations in this study. First, this was a retrospective study with a small number of patients, which might have resulted in potential bias despite the use of the propensity score methodology.

Second, the follow-up period was at least two-fold longer in the control group relatively to the NHT group. Because there was insufficient evidence supporting the notion that NHT provides long-term benefits in patients with $\mathrm{CaP}$ in the current guidelines, we initiated NHT in locally advanced patients with CaP after 2009 (the first NHT case received RaLP in Aug. 2009 after 4 months of NHT). A significant longer follow-up period in the RaLPalone arm might account for the increased number of events. Although most BCR occurred during the first year after RaLP and all enrolled patients in the NHT group had at least one year of follow-up, this unequal follow-up period might have led to under-estimations of late BCR in the NHT group.

Third, we did not routinely follow-up testosterone levels after RaLP. This could have been useful for evaluating the residual effects of pre-operative androgen deprivation.

Finally, successful treatment of $\mathrm{CaP}$ was evaluated by the degree of oncologic control achieved in this study, but this did not take into account other important factors, such as parameters which predict quality of life including continence and erectile function. However, erectile function was difficult to evaluate as hormone therapy might have compromised sexual function and produced a confounding negative effect.

\section{Conclusion}

In this preliminary study, NHT prior to RaLP in patients with intermediate- or high-risk $\mathrm{CaP}$ seemed to provide potential benefits including shorter operative time, reduced blood loss, and shorter period of Foley catheterization. In patients with pre-treatment PSA $10-20 \mathrm{ng} / \mathrm{ml}$ and PSA>50 ng/ml, NHT might decrease the incidence of early BCR and overall BCR during postoperative one and half years. NHT might also have protective effects on early BCR in patients with pretreatment PSA $20-50 \mathrm{ng} / \mathrm{ml}$. Further study is warranted to determine the clinical implications and optimal periods of NHT followed by RaLP. 


\section{Conflicts of Interest}

None of the contributing authors have any conflict of interest, including specific financial interests or relationships and affiliations relevant to the subject matter or materials discussed in the manuscript.

\section{References}

1 Köllermann J, Feek U, Müller H, Kaulfuss U, Oehler U, Helpap $B$ and Köllermann MW: Nondetected tumor (pT0) after prolonged, neoadjuvant treatment of localized prostatic carcinoma. Eur Urol 38(6): 714-720, 2000.

2 Fair WR, Cookson MS, Stroumbakis N, Cohen D, Aprikian AG, Wang Y, Russo P, Soloway SM, Sogani P, Sheinfeld J, Herr H, Dalgabni G, Begg CB, Heston WD and Reuter VE: The indications, rationale, and results of neoadjuvant androgen deprivation in the treatment of prostatic cancer: Memorial SloanKettering Cancer Center results. Urology 49(3A Suppl): 46-55, 1997.

3 Schulman CC, Debruyne FM, Forster G, Selvaggi FP, Zlotta AR and Witjes WP: 4-Year follow-up results of a European prospective randomized study on neoadjuvant hormonal therapy prior to radical prostatectomy in T2-3N0M0 prostate cancer. European Study Group on Neoadjuvant Treatment of Prostate Cancer. Eur Urol 38(6): 706-713, 2000.

4 Cookson MS, Sogani PC, Russo P, Sheinfeld J, Herr H, Dalbagni G, Reuter VE, Begg CB and Fair WR: Pathological staging and biochemical recurrence after neoadjuvant androgen deprivation therapy in combination with radical prostatectomy in clinically localized prostate cancer: results of a phase II study. Br J Urol 79(3): 432-438, 1997.

5 Shelley MD, Kumar S, Wilt T, Staffurth J, Coles B and Mason MD: A systematic review and meta-analysis of randomised trials of neo-adjuvant hormone therapy for localised and locally advanced prostate carcinoma. Cancer Treat Rev 35(1): 9-17, 2009.

6 Brown JA, Garlitz C, Strup SE, Hubosky SG and Gomella L: Laparoscopic radical prostatectomy after neoadjuvant hormonal therapy: an apparently safe and effective procedure. J Laparoendosc Adv Surg Tech A 14(6): 335-338, 2004.

7 Scolieri MJ, Altman A and Resnick MI: Neoadjuvant hormonal ablative therapy before radical prostatectomy: a review. Is it indicated. J Urol 164(5): 1465-1472, 2000.

8 Fair WR and Betancourt JE: Update on Memorial SloanKettering Cancer Center studies of neoadjuvant hormonal therapy for prostate cancer. Mol Urol 4(3): 241-248; discussion 249-250, 2000.

9 Soloway MS, Pareek K, Sharifi R, Wajsman Z, McLeod D, Wood DP Jr. and Puras-Baez A; Lupron Depot Neoadjuvant Prostate Cancer Study Group: Neoadjuvant androgen ablation before radical prostatectomy in cT2bNxMo prostate cancer: 5year results. J Urol 167(1): 112-116, 2002.

10 Aus G, Abrahamsson PA, Ahlgren G, Hugosson J, Lundberg S, Schain M, Schelin S and Pedersen K: Three-month neoadjuvant hormonal therapy before radical prostatectomy: a 7-year followup of a randomized controlled trial. BJU Int 90(6): 561-566, 2002.

11 Gleave ME, La Bianca SE, Goldenberg SL, Jones EC, Bruchovsky $\mathrm{N}$ and Sullivan LD: Long-term neoadjuvant hormone therapy prior to radical prostatectomy: evaluation of risk for biochemical recurrence at 5-year follow-up. Urology 56(2): 289-294, 2000

12 Hagiwara K, Koie T, Ohyama C, Yamamoto O, Imai A, Hatakeyama S, Yoneyama T, Hashimoto Y, Tobisawa Y and Yoneyama T: Efficacy of a neoadjuvant gonadotropin-releasing hormone antagonist plus low-dose estramustine phosphate in high-risk prostate cancer: a single-center study. Int Urol Nephrol, 2017. doi: 10.1007/s11255-017-1546-6. [Epub ahead of print]

13 Narita T, Koie T, Ookubo T, Mitsuzuka K, Narita S, Yamamoto H, Inoue T, Hatakeyama S, Kawamura S, Tochigi T, Habuchi T, Arai Y and Ohyama C: The impact of extended lymph node dissection versus neoadjuvant therapy with limited lymph node dissection on biochemical recurrence in high-risk prostate cancer patients treated with radical prostatectomy: a multi-institutional analysis. Med Oncol 34: 1, 2017.

14 Berglund RK, Tangen CM, Powell IJ, Lowe BA, Haas GP, Carroll PR, Canby-Hagino ED, deVere White R, Hemstreet GP 3rd, Crawford ED, Thompson IM Jr. and Klein EA: Ten-year follow-up of neoadjuvant therapy with goserelin acetate and flutamide before radical prostatectomy for clinical T3 and T4 prostate cancer: update on Southwest Oncology Group Study 9109. Urology 79: 633-637, 2012.

15 Witjes WP, Schulman CC and Debruyne FM: Preliminary results of a prospective randomized study comparing radical prostatectomy versus radical prostatectomy associated with neoadjuvant hormonal combination therapy in T2-3 N0 M0 prostatic carcinoma. The European Study Group on Neoadjuvant Treatment of Prostate Cancer. Urology 49(3A Suppl): 65-69, 1997.

16 Pettaway CA, Pisters LL, Troncoso P, Slaton J, Finn L, Kamoi $\mathrm{K}$ and Logothetis CJ: Neoadjuvant chemotherapy and hormonal therapy followed by radical prostatectomy: feasibility and preliminary results. J Clin Oncol 18(5): 1050-1057, 2000.

17 Narita S, Tsuchiya N, Kumazawa T, Maita S, Numakura K, Obara T, Tsuruta H, Saito M, Inoue T, Horikawa Y, Satoh S, Nanjyo $\mathrm{H}$ and Habuchi $\mathrm{T}$ : Short-term clinicopathological outcome of neoadjuvant chemohormonal therapy comprising complete androgen blockade, followed by treatment with docetaxel and estramustine phosphate before radical prostatectomy in Japanese patients with high-risk localized prostate cancer. World J Surg Oncol 10: 1, 2012.

18 Chi KN, Chin JL, Winquist E, Klotz L, Saad F and Gleave ME: Multicenter phase II study of combined neoadjuvant docetaxel and hormone therapy before radical prostatectomy for patients with high risk localized prostate cancer. J Urol 180(2): 565-570, 2008.

19 Prayer-Galetti T, Sacco E, Pagano F, Gardiman M, Cisternino A, Betto $\mathrm{G}$ and Sperandio P: Long-term follow-up of a neoadjuvant chemohormonal taxane-based phase II trial before radical prostatectomy in patients with non-metastatic high-risk prostate cancer. BJU Int 100(2): 274-280, 2007.

20 Dreicer R, Magi-Galluzzi C, Zhou M, Rothaermel J, Reuther A, Ulchaker J, Zippe C, Fergany A and Klein EA: Phase II trial of neoadjuvant docetaxel before radical prostatectomy for locally advanced prostate cancer. Urology 63(6): 1138-1142, 2004.

21 Takeda T, Miyajima A, Kaneko G, Kikuchi E, Nakagawa K and Oya M: Androgen deprivation therapy improves pneumoperitoneum time during laparoscopic radical prostatectomy in Japanese patients with enlarged prostates. Asian J Endosc Surg $7(2): 145-151,2014$ 
22 Ou YC, Yang CK, Chang KS, Wang J, Hung SW, Tung MC, Tewari AK and Patel VR: Prevention and Management of Complications During Robotic-assisted Laparoscopic Radical Prostatectomy Following Comprehensive Planning: A Large Series Involving a Single Surgeon. Anticancer Res 36: 19911998, 2016.

23 Ou YC, Yang CK, Kang HM, Chang KS, Wang J, Hung SW, Tung MC, Tewari AK and Patel VR: Pentafecta Outcomes of 230 Cases of Robotic-assisted Radical Prostatectomy with Bilateral Neurovascular Bundle Preservation. Anticancer Res 35: 5007-5013, 2015.

24 MG O: Time to normalization of serum testosterone after 3month luteinizing hormone-releasing hormone agonist administered in the neoadjuvant setting: implications for dosing schedule and neoadjuvant study consideration. J Urol 160(5): 1685-1688, 1998.

25 Hall MC, Fritzsch RJ, Sagalowsky AI, Ahrens A, Petty B and Roehrborn CG: Prospective determination of the hormonal response after cessation of luteinizing hormone-releasing hormone agonist treatment in patients with prostate cancer. Urology 53(5): 898-902; discussion 902-893, 1999.

26 Koie T, Mitsuzuka K, Yoneyama T, Narita S, Kawamura S, Kaiho Y, Tsuchiya N, Tochigi T, Habuchi T, Arai Y, Ohyama C, Yoneyama $\mathrm{T}$ and Tobisawa $\mathrm{Y}$ : Neoadjuvant luteinizing-hormonereleasing hormone agonist plus low-dose estramustine phosphate improves prostate-specific antigen-free survival in high-risk prostate cancer patients: a propensity score-matched analysis. Int J Clin Oncol 20: 1018-1025, 2015.
27 Gleave ME, Goldenberg SL, Chin JL, Warner J, Saad F, Klotz LH, Jewett M, Kassabian V, Chetner M, Dupont C and Van Rensselaer S; Canadian Uro-Oncology Group: Randomized comparative study of 3 versus 8 -month neoadjuvant hormonal therapy before radical prostatectomy: biochemical and pathological effects. J Urol 66(2): 500-506; discussion 506-507, 2001 .

28 Kumar S, Shelley M, Harrison C, Coles B, Wilt TJ and Mason MD: Neo-adjuvant and adjuvant hormone therapy for localised and locally advanced prostate cancer. Cochrane Database Syst Rev 4: CD006019, 2006.

29 Meyer F, Moore L, Bairati I, Lacombe L, Têtu B and Fradet Y: Neoadjuvant hormonal therapy before radical prostatectomy and risk of prostate specific antigen failure. J Urol 162(6): 2024$2028,1999$. 